\title{
Prognostic factors for survival in patients with metastatic renal cell carcinoma treated with targeted therapies
}

\author{
G Procopio*,I, E Verzoni', R lacovelli' ${ }^{2}$, D Biasoni ${ }^{3}$, I Testa', L Porcu $^{4}$ and F De Braud \\ 'Department of Medical Oncology, Fondazione IRCCS Istituto Nazionale dei Tumori, Via G. Venezian I, 20133 Milan, Italy; ${ }^{2}$ Department of Medical \\ Oncology, Sapienza University, Rome, Italy; ${ }^{3}$ Department of Urology, Fondazione IRCCS Istituto Nazionale dei Tumori, Milan, Italy; ${ }^{4}$ Methodology for \\ Biomedical Research, Mario Negri Institute for Pharmacological Research, Milan, Italy
}

\begin{abstract}
BACKGROUND: The most important prognostic factors for survival in patients with metastatic renal cell carcinoma (mRCC) were evaluated in the era of cytokine therapy, and only recently were revalidating in patients receiving targeted therapies (TTs).

METHODS: Clinical data for consecutive patients with $\mathrm{mRCC}$ who received TTs were retrieved from the database of Istituto Nazionale dei Tumori of Milan. Variables with a significant association with overall survival (OS) were estimated by proportional hazard regression, and a backward stepwise multivariate analysis identified the independent prognostic factors.

RESULTS: Data for 336 consecutive patients treated with TTs for RCC during the period 2004-20 I I were evaluated. According to the Motzer classification, 32\% patients were low risk, $48 \%$ were intermediate risk and $20 \%$ were poor risk. One hundred and sixty-seven (49.7\%) patients received one TT, I I 6 (34.5\%) received a second-line TT, 42 (I2.5\%) a third-line TT and II (3.3\%) patients received a fourth-line TT. The median OS was 24 months (95\% Cl 20.0, 27.0) and the 5-year OS rate was 24.6\% (95\% Cl I8.7, 30.8\%). In the uni- and multivariate analysis Motzer risk classification, Fuhrman grade and previous cytokine therapy were identified as independent prognostic factors $(P<0.01)$.

CONCLUSION: The Motzer classification was confirmed as an independent prognostic factor for OS in patients with mRCC receiving TTs. Additionally, Fuhrman grade and previous cytokine therapy were independent prognostic factors for clinical outcome. British Journal of Cancer (2012) 107, 1227-1232. doi:I0.1038/bjc.2012.327 www.bjcancer.com

Published online II September 2012
\end{abstract}

(c) 2012 Cancer Research UK

Keywords: renal carcinoma; targeted therapies; tyrosine kinase inhibitors; prognostic factors; angiogenesis

The management of metastatic renal cell carcinoma (mRCC) has been revolutionized, with targeted therapies (TTs) superseding cytokine therapy (interferon- $\alpha$ and interleukin-2). Indeed, because of the number of therapies now available, the identification of prognostic factors has an important role in the clinical management of the advanced disease (Heng et al, 2009; Volpe and Patard, 2010).

Prognostic factors allow a homogeneous stratification of patients in clinical trials, avoiding the identification of any group in which a TT has greater activity, which would constitute a selection bias (Motzer et al, 2000).

In the cytokine era, the most commonly used prognostic criteria have been those developed by Motzer, who assessed 670 patients enroled in clinical trials of immunotherapy and chemotherapy at the Memorial Sloan Kettering Cancer Centre (Motzer et al, 1999). The multivariate analysis has revealed that haemoglobin, serum lactate dehydrogenase, corrected serum calcium level, nephrectomy status and Karnofsky Performance Status (PS) were independent risk factors for prediction of survival.

Using a combination of these factors, patients were stratified as being of favourable, intermediate or poor risk, with mean survival times of 20, 10 and 4 months, respectively.

\footnotetext{
*Correspondence: Dr G Procopio;

E-mail: giuseppe.procopio@istitutotumori.mi.it

Received 13 March 2012; revised 23 May 2012; accepted 29 May 2012;

published online II September 2012
}

The predictive role of this model has been successfully validated, with some modifications, by a retrospective analysis that included 353 patients with mRCC at the Cleveland Clinic (Mekhail et al, 2005).

This study confirms the prognostic role for all factors identified by Motzer, with the exclusion of PS, and reveals two more prognostic factors: prior radiotherapy and number of sites of metastases.Reported median survival times were 26.0, 14.4 and 7.3 months, respectively (Mekhail et al, 2005).

Despite their validation only in patients treated with cytokines, these models have also frequently been used to assess the risk of death in patients treated with TTs in major phase II-III trials in mRCC.

Choueiri et al (2007) proposed a new classification for patients receiving antiangiogenic agents, confirming the independent predictive role for Eastern Cooperative Oncology Group (ECOG) PS, time from diagnosis to current treatment and abnormal baseline-corrected serum calcium and revealing higher platelet and absolute neutrophil counts as two new prognostic factors.

Similar to the previous classification, patients were grouped according to the number of prognostic factors $(\leqslant 1,2$ or $\geqslant 3$ prognostic factors) and a difference in median overall survival (mOS) was found (20.1, 13 and 3.9 months, respectively) (Choueiri et al, 2007). The largest analysis in patients with mRCC treated with TT was performed by Heng et al (2009). In this study, the role of low haemoglobin, high serum-corrected calcium, Karnofsky PS $<80$ and time from diagnosis to therapy initiation $<1$ year were 
confirmed as independent predictors of shorter survival. Furthermore the absolute neutrophil and platelet counts greater than the upper limit of normal were also considered prognostic factors.

The mOS was not reached in the favourable-risk group, but was 27.0 and 8.8 months in the intermediate-risk and poor-risk groups, respectively (Heng et al, 2009).

This study did not report a difference in outcomes with the use of antiangiogenic therapy as first- or second-line therapy, and confirms the poor prognosis for non-clear-cell histology, although this factor was not included in the final model (Heng et al, 2009).

Recently Manola et al (2011) reported the results from the International Kidney Cancer Working Group, which validated the role of prognostic factors for survival in patients with mRCC. From a comprehensive international database, data for 3748 patients with mRCC were analysed to identify independent predictors of survival.Nine clinical factors were considered in this analysis; treatment, PS, number of metastatic sites, time from diagnosis to treatment, pretreatment haemoglobin, white blood count, lactate dehydrogenase, alkaline phosphatase and serum calcium.These factors formed three risk groups using the 25th and 75th percentiles of the resulting prognostic index.This model showed good concordance among the 645 patients treated with tyrosine kinase inhibitors $(C$ statistic $=0.741 ; 95 \%$ CI $0.714,0.768)$.

All these studies show that TTs have approximately doubled the median survival in patients with mRCC compared with the data reported by Motzer in the cytokine era (22 vs 10 months) and that the efficacy of sequential TTs is independent of the treatment sequence used.

Some questions remain unanswered; no factor has been reported as prognostic for patients receiving mammalian target of rapamycin inhibitors, and the role of nephrectomy is still undefined as a prognostic factor in patients with $\mathrm{mRCC}$ receiving TTs.

A series of consecutive patients with mRCC and treated with TTs at IRCCS Istituto Nazionale dei Tumori in Milan were examined to evaluate the role of several prognostic factors. The preliminary results of this retrospective study have been published previously (Procopio et al, 2011a).

\section{MATERIALS AND METHODS}

\section{Patients}

Consecutive patients with mRCC, aged $\geqslant 18$ years and with an ECOG PS of 0,1 or 2, who were treated with one or more TTs, were eligible for inclusion in this retrospective study. Baseline characteristics and outcomes of patients were collected from the database of Istituto Nazionale dei Tumori, Milan, Italy.

A number of patients enrolled in this study had previously taken part in a range of prospective trials including TARGET (Escudier et al, 2007a), the EU-ARCCS (Beck et al, 2011), RECORD-1 (Motzer et al, 2008), AXIS (Rini et al, 2011), AVOREN (Escudier et al, 2007b) and ROSORC (Procopio et al, 2011b).

The study was conducted in accordance with the International Conference on Harmonization for Good Clinical Practice (Dixon, 1998), and it was approved by the local ethics committee and institutional review board.

\section{Treatment and study assessments}

All patients included in the final database received TT as first-line treatment, or subsequent cytokine therapy. The TTs were: sorafenib $400 \mathrm{mg}$ twice daily orally, sunitinib $50 \mathrm{mg}$ daily (4 weeks on, 2 weeks off) orally, bevacizumab $10 \mathrm{mg} / \mathrm{kg}$ intravenously every 2 weeks in combination with subcutaneous interferon- $\alpha$, everolimus $10 \mathrm{mg}$ daily orally, temsirolimus $25 \mathrm{mg}$ intravenously weekly or axitinib $10 \mathrm{mg}$ daily orally. Patients received systemic therapy until disease progression or the presence of serious adverse events.

\section{Statistical analyses}

For the description of clinical, pathological and treatment characteristics of the patients, categorical variables were described using absolute and relative frequencies; continuous variables were described using the median as a measure of central tendency and the range as a measure of dispersion. $\chi^{2}$ test for trend was performed in order to determine whether Motzer classification was a significant predictor of the number of therapy cycles. Overall survival was defined as the time from initiation of treatment with TTs to the date of death or last follow-up. The Kaplan-Meier method was used to estimate survival probabilities; the inverse Kaplan-Meier method was used to estimate the median follow-up; the log-rank test was used to detect a statistically significant difference in survival; the Cox regression model was used to estimate hazard ratios (HRs) and to identify independent prognostic factors by using a backward selection strategy; all the baseline characteristics were introduced in the backward selection algorithm. All statistical tests were two-sided and a $P$-value $<0.05$ was considered statistically significant; the same threshold was used as the criterion for retaining variables in the backward selection algorithm.. Statistical analysis was performed using SAS software, version 9.2 (SAS Institute, Cary, NC, USA); the statistical package Stata, version 12.0 (StataCorp, College Station, TX, USA) was used for Kaplan-Meier plots.

\section{RESULTS}

\section{Patients and treatments}

A total of 336 patients with mRCC were treated with TTs at the Istituto Nazionale dei Tumori in Milan between January 2004 and October 2011 (Supplementary Figure 1, flow chart). Patient characteristics at baseline are shown in Table 1. For the definition of Motzer risk groups the following factors were considered: ECOG PS status as 0 vs 1 and above, nephrectomy status, $\mathrm{HgB}, \mathrm{LDH}$ and corrected calcium. Similar to the previous classification, patients were grouped according to the number of prognostic factors $(0,1-2$ or $\geqslant 3)$ in low, intermediate and poor risk, respectively.

According to the Motzer classification 108 (32\%) patients were low risk, $159(48 \%)$ intermediate and $66(20 \%)$ poor risk

Nine patients were excluded from survival analysis: seven patients with Bellini duct carcinoma characterised by an aggressive course and two patients because survival outcome was not available. Patients were followed for a median of 43 months (range 0.5-88.1 months). Median overall survival was 24 months (95\% CI: $20.0,27.0)$ and the 5-year overall survival rate was 24.6\% (95\% CI: 18.7, 30.8) (Figure 1). Overall 199 (57\%) patients died.

One hundred and sixty-seven (49.7\%) patients received only one TT, $116(34.5 \%)$ received a second-line TT, $42(12.5 \%)$ a thirdline and $11(3.3 \%)$ patients received a fourth-line TT; overall 245 (72.9\%) patients received sorafenib, 212 (63.1\%) sunitinib, 33 (9.8\%) bevacizumab and $73(21.7 \%)$ another/other TT(s).

The majority of patients $(n=295,87.8 \%)$ received sorafenib or sunitinib as the first TT; of these, $205(61.0 \%)$ patients received sorafenib; of the remaining patients $28(8.3 \%)$ received bevacizumab, $8(2.4 \%)$ temsirolimus, $3(0.9 \%)$ bevacizumab in combination with everolimus, $1(0.3 \%)$ bevacizumab in combination with erlotinib and, $1(0.3 \%)$ pazopanib.With regard to second-line treatment, sorafenib was followed by sunitinib in 101 out of 111 $(91.0 \%)$ patients and sunitinib was followed by sorafenib in 19 out of $29(65.5 \%)$ patients. 
Table I Baseline characteristics of the patient population with metastatic renal cell carcinoma treated with targeted therapies

\begin{tabular}{|c|c|c|}
\hline Characteristics & $N$ & $\%$ \\
\hline Median age, years (range) & $62(25-82)$ & \\
\hline \multicolumn{3}{|l|}{ Sex } \\
\hline Male & 248 & 73.8 \\
\hline Female & 88 & 26.2 \\
\hline \multicolumn{3}{|l|}{ ECOG PS } \\
\hline 0 & 186 & 55.4 \\
\hline I & 131 & 39.0 \\
\hline 2 & 19 & 5.7 \\
\hline \multicolumn{3}{|l|}{ Histology } \\
\hline Clear-cell & 291 & 86.9 \\
\hline Non-clear cell & 45 & 13.1 \\
\hline Papillary & 29 & 65.9 \\
\hline Bellini & 7 & 15.9 \\
\hline Chromophobe & 7 & 15.9 \\
\hline Oncocytoma & I & 2.3 \\
\hline Missing data & I & 0.3 \\
\hline \multicolumn{3}{|l|}{ Previous nephrectomy } \\
\hline Yes & 293 & 87.2 \\
\hline No & 43 & 12.8 \\
\hline \multicolumn{3}{|l|}{ Fuhrman grade } \\
\hline I & 15 & 5.1 \\
\hline 2 & 99 & 33.8 \\
\hline 3 & 131 & 44.7 \\
\hline 4 & 48 & 16.4 \\
\hline Missing data & 43 & 12.8 \\
\hline \multicolumn{3}{|l|}{ Motzer risk class } \\
\hline Low risk & 108 & 32.4 \\
\hline Intermediate risk & 159 & 47.7 \\
\hline High risk & 66 & 19.8 \\
\hline Missing data & 3 & 0.9 \\
\hline \multicolumn{3}{|l|}{ Number of disease sites } \\
\hline I & 126 & 37.8 \\
\hline 2 & 117 & 35.1 \\
\hline 3 & 67 & 20.1 \\
\hline 4 & 18 & 5.4 \\
\hline 5 & 4 & 1.2 \\
\hline 6 & I & 0.3 \\
\hline Missing data & 3 & 0.9 \\
\hline \multicolumn{3}{|l|}{ Sites of disease $(n=659)$} \\
\hline Bone & 94 & 28.2 \\
\hline Brain & 16 & 4.8 \\
\hline Liver & 62 & 18.6 \\
\hline Lung & 221 & 66.4 \\
\hline Lymph nodes & 127 & 38.1 \\
\hline Pancreas & 17 & 5.1 \\
\hline Thyroid & 5 & 1.5 \\
\hline Other & 117 & 35.1 \\
\hline Missing data & 3 & 0.9 \\
\hline
\end{tabular}

\section{Treatment outcomes}

Regarding the association between the Motzer classification and the number of therapy cycles, a negative trend was detected $\left(\chi^{2}=10.718, P=0.001\right)$; the median number of treatments was two in the low and intermediate risk groups, and one in the high-risk group. Regarding patients who received at least a secondline therapy, there was no significant correlation between the sequence of $\mathrm{TT}$ and survival $\left(\mathrm{HR}_{\text {sunitinib } \rightarrow \text { sorafenib/sorafenib } \rightarrow}\right.$ sunitinib $=1.16 ; 95 \% \mathrm{CI}: 0.57-2.33 ; \mathrm{HR}_{\mathrm{Other} / \text { sorafenib } \rightarrow \text { sunitinib }}=1.21$; 95\% CI: $0.78-1.88 ; P=0.674$ ) as presented in Table 2 and Figure 2.

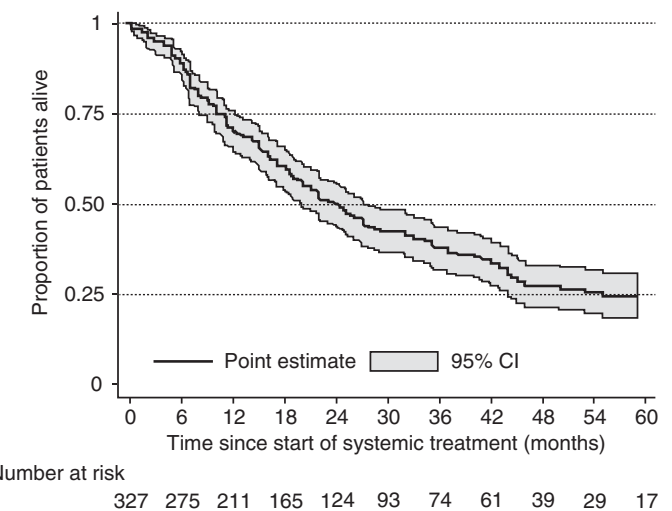

Figure I Overall survival in patients with metastatic renal cell carcinoma receiving targeted therapies.

\section{Prognostic factors}

At the univariate level, Motzer risk class, ECOG PS, nephrectomy, Fuhrman grade, number of sites of disease and previous cytokine treatment were predictive factors for survival, but there were no differences based on tumour histology, age, sex or treatment sequence (Table 2).

Median survival and 5-year overall survival rate according to the Motzer criteria were 44 months (95\% CI 33.0, 63.1) and $40.0 \%$ (95\% CI 28.4, 51.3) in low-risk patients, 22 months (95\% CI 17.0, $27.0)$ and $21.4 \%(95 \%$ CI $12.8,31.4)$ in intermediate-risk patients and 9 months $(95 \%$ CI $7.0,11.0)$ and $0 \%$ in patients considered high risk $(P<0.001)$ (Figure $3 \mathrm{~A})$.

The multivariate analysis identified the following independent prognostic factors: Motzer score $\left(\mathrm{HR}_{\text {intermediate_vs_low }}=2.39 ; 95 \%\right.$ CI 1.67, 3.41; HR high_vs_low $_{1}=7.41 ; 95 \%$ CI $\left.4.89,11.24 ; P<.001\right)$; Fuhrman grade $\left(\mathrm{HR}_{3-4 \_ \text {vs_ } 1-2}=1.59 ; 95 \%\right.$ CI $\left.1.19,2.12 ; P=0.002\right)$ and previous cytokines $\left(\mathrm{HR}_{\text {yes vs no }}=1.50 ; 95 \% \mathrm{CI} 1.13,2.00\right.$; $P=0.005)$. Adjusting for all baseline characteristics statistically associated to overall survival nephrectomy confirmed its prognostic role $(\mathrm{HR}=0.52 ; 95 \% \quad \mathrm{CI}: 0.32-0.82 ; \quad P=0.006)$ (Figure 3B-D) (Supplementary Tables 1 and 2).

\section{DISCUSSION}

The high level of molecular and pathological heterogeneity in RCC contributes to the varying prognoses and outcomes that characterise this disease (Ljungberg et al, 1996). A more detailed knowledge and understanding of the individual risk factors that predict patient's responses would be beneficial not only for individual patient management and treatment choices, but also for clinical trial design to ensure better definition of patient risk groups (Ljungberg et al, 1996; Volpe and Patard, 2010).

Several prognostic factors have been established for the outcomes of patients with advanced RCC. The majority of the research on this topic applies to the treatment with cytokines, interferon- $\alpha$ and interleukin-2 (Motzer et al, 1999, 2000, 2004; Mekhail et al, 2005; Choueiri et al, 2007). With the subsequent introduction of novel targeted anticancer therapies, the models of prognostic factors are required to be revalidated for the new treatments.

With regard to the new therapies for patients with mRCC, Manola et al (2011) validated nine prognostic factors and developed a prognostic model for survival, including three risk groups (favourable, intermediate and poor) characterised by 26.9, 11.5 and 4.2 months of overall survival, respectively. This study was the largest of its kind, validating the role of prognostic factors in a population receiving TTs. 
Table 2 Univariate overall survival analysis for patients with metastatic renal cell carcinoma treated with targeted therapies

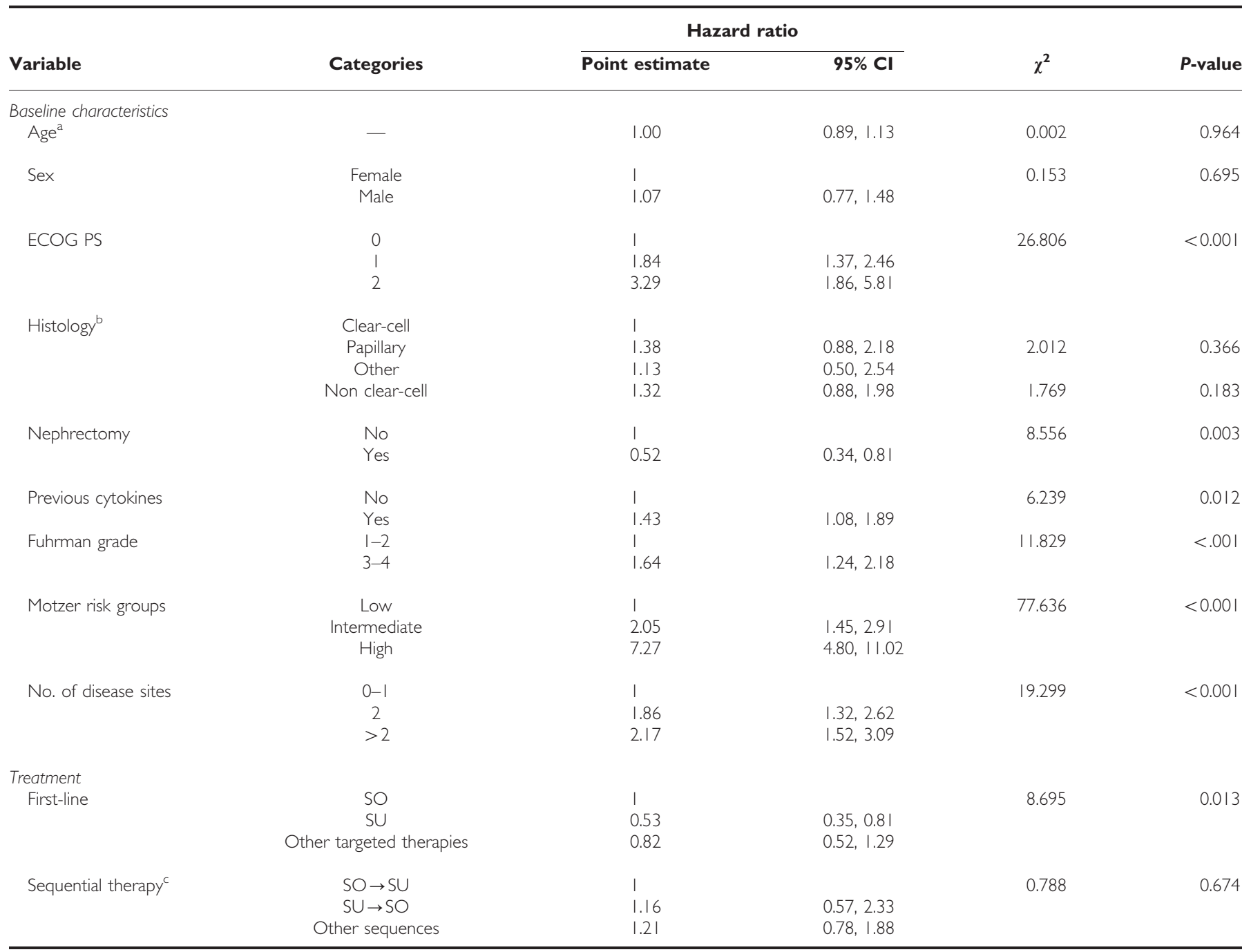

Abbreviations: $\mathrm{Cl}=$ confidence interval; ECOG PS = Eastern Cooperative Oncology Group Performance Status; SO = sorafenib; SU = sunitinib. ${ }^{a}$ Age in I0-year increments. ${ }^{\mathrm{b}}$ Two main histological classifications included. In patients receiving a second targeted therapy.

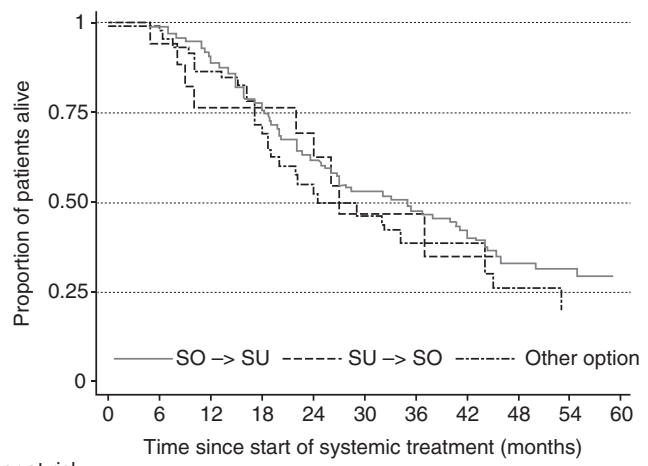

Number at risk

$\begin{array}{cccccccccccc}\text { SO } \rightarrow \text { SU } & 100 & 99 & 91 & 76 & 60 & 51 & 45 & 38 & 26 & 19 & 9 \\ \text { SU } \rightarrow \text { SO } & 19 & 17 & 13 & 12 & 10 & 5 & 4 & 1 & 0 & 0 & 0 \\ \text { Other option } & 47 & 46 & 40 & 32 & 21 & 14 & 10 & 9 & 6 & 4 & 4\end{array}$

Figure 2 Overall survival with sorafenib and sunitinib compared with other therapies in patients with metastatic renal cell carcinoma.

For patients receiving TTs (mostly sorafenib, sunitinib and bevacizumab), our study highlighted the prognostic role of the Motzer classification according to the uni- and multivariate analyses. Similar to that previously reported by Heng et al (2009), the mOS of patients described in this report was notably increased compared with that demonstrated by Motzer et al (1999).

The increased survival reported for patients with mRCC may well be associated with the improvement of diagnostic and surgical procedures and best supportive care, but it is also due to the greater efficacy of the new systemic therapies. Moreover, this survival improvement has been reported for all risk groups; the mOS was 43, 21 and 8 months for favourable-, intermediate- and poor-risk groups, respectively, which is double the overall survival reported previously for patients treated with cytokines $(20,10$ and 4 months, respectively) (Motzer et al, 2004).

There was no survival difference for different treatment sequences or types of TTs received, as discussed in a previous study (Procopio et al, 2011a, b).

Among the parameters of the Motzer risk classification, the univariate analysis showed nephrectomy as an independent variable prognostic factor for survival in patients treated with TTs. The prognostic role of cytoreductive nephrectomy $(\mathrm{CN})$ in patients affected by mRCC was first reported by Motzer et al (1999), and subsequently confirmed by two prospective studies, which showed a longer overall survival with $\mathrm{CN}$ combined with 
A

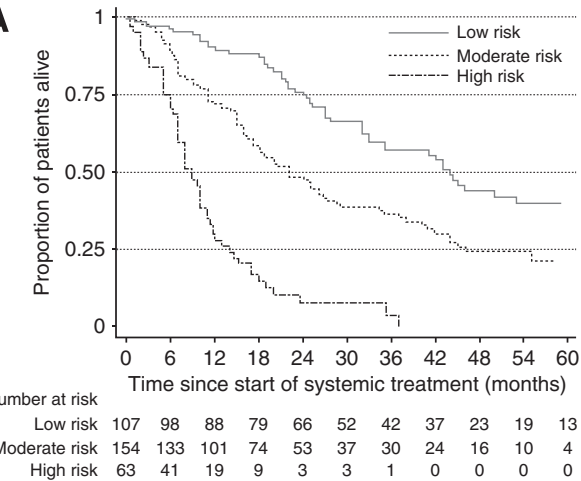

C

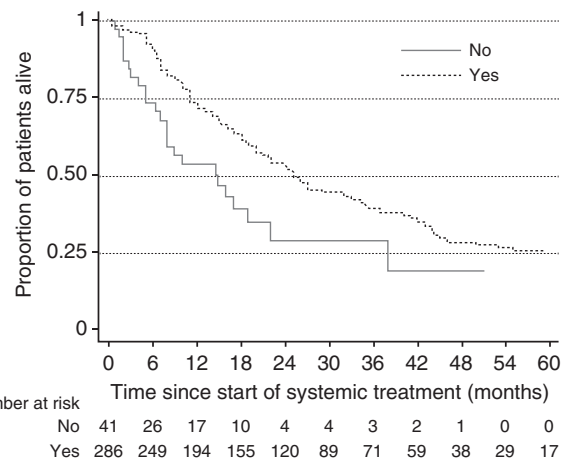

B

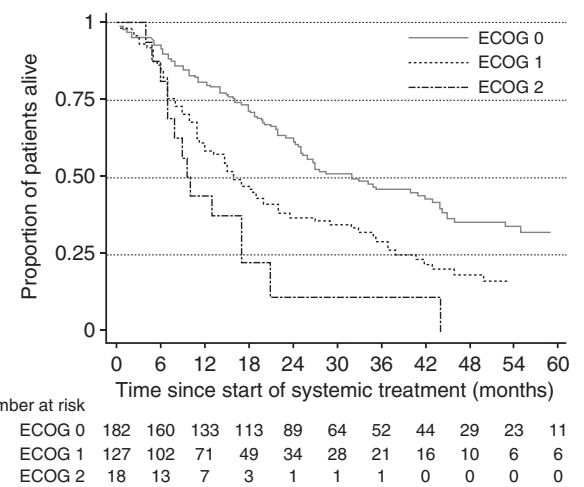

D

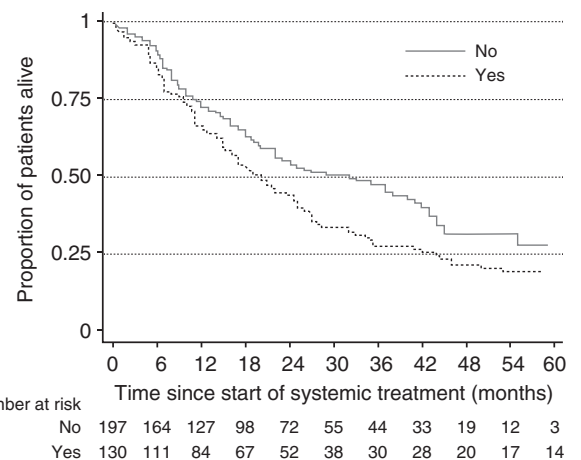

Figure 3 Overall survival in patients with metastatic renal cell carcinoma receiving targeted therapies stratified according to (A) Motzer classification, (B) Eastern Cooperative Oncology Group performance status (ECOG PS), (C) nephrectomy status and (D) previous cytokine therapy.

Table 3 Multivariate overall survival analysis for patients with metastatic renal cell carcinoma treated with targeted therapies

\begin{tabular}{|c|c|c|c|c|c|}
\hline \multirow[b]{2}{*}{ Variable } & \multirow[b]{2}{*}{ Categories } & \multicolumn{2}{|c|}{ Hazard ratio } & \multirow[b]{2}{*}{$\chi^{2}$} & \multirow[b]{2}{*}{$P$-value } \\
\hline & & $\begin{array}{c}\text { Point } \\
\text { estimate }\end{array}$ & $95 \% \mathrm{Cl}$ & & \\
\hline \multirow{2}{*}{$\begin{array}{l}\text { Previous cytokine } \\
\text { therapy }\end{array}$} & No & । & & 7.909 & 0.005 \\
\hline & Yes & 1.50 & $1.131,2.00$ & & \\
\hline \multirow[t]{2}{*}{ Fuhrman grade } & $1-2$ & । & & 10.008 & 0.002 \\
\hline & $3-4$ & 1.59 & $1.193,2.12$ & & \\
\hline \multirow[t]{3}{*}{ Motzer risk groups } & Low & । & & 89.712 & $<0.001$ \\
\hline & Intermediate & 2.39 & $1.67,3.41$ & & \\
\hline & High & 7.41 & $4.89,11.24$ & & \\
\hline
\end{tabular}

Abbreviation: $\mathrm{Cl}=$ confidence interval.

cytokine therapy than with systemic treatments alone (Flanigan et al, 2001 and Mickisch et al, 2001).

Recently, the role of $\mathrm{CN}$ has been questioned, considering the high-response rate and the improvement of survival achieved with TTs (You et al, 2011). Although the prognostic role of previous nephrectomy has been recently reported in patients with mRCC treated with TTs (Choueiri et al, 2011; Yuasa et al, 2012), the analysis of prognostic factors for patients enrolled in a phase III trial of sunitinib failed to find it (Patil et al, 2011). Furthermore, the role of $\mathrm{CN}$ on tumour control by TTs is also disputed, as two large retrospective analyses report conflicting results (Choueiri et al, 2011; Patil et al, 2011).

Our study, larger than that published by Yuasa et al (2012) and similar to that of Choueiri et al (2011), regarding the number of patients and the type of treatments, reports a survival benefit and the independent prognostic role of $\mathrm{CN}$ in patients with mRCC treated with TTs.
The current prognostic role of $\mathrm{CN}$ in patients with mRCC treated with TTs is therefore not yet clearly defined and probably only ongoing phase III trials will in time answer this question (You et al, 2011). Proof of that considering only our retrospective analysis patients who did not receive a $\mathrm{CN}$ often had bad clinical conditions or multiple sites of disease and bulky disease. Therefore, this last population had additional unfavourable factors that could explain the worse prognosis of the disease.

Additionally the uni- and multivariate analyses showed the Fuhrman grade and previous therapy with cytokines as independent factors of clinical outcome. In our experience, patients treated with cytokines received too-late TTs for advanced disease, and often only one antiangiogenic treatment, which could, in our opinion, justify the worse prognosis of this subgroup of population.

Fuhrman grade is well-recognised to be an independent prognostic factor for recurrence in patients nephrectomised.

Our experience disclosed that also in advanced disease treated with TTs, Fuhrman grade could have a role as independent prognostic factor for outcome (see Tables 2 and 3).

Additionally, some factors, such as number of sites of disease and number of TTs, were confirmed as prognostic factors only in the univariate analysis, suggesting that they may be less relevant (Table 2).

With this study being designed to elucidate prognostic factors in mRCC, its retrospective design constitutes a distinct limitation on the interpretation of results. Also not considered in this study was the heterogeneity, which usually characterises mRCC and any biological parameters.

In conclusion, the Motzer criteria were validated as prognostic factors for survival in patients with mRCC receiving TTs. Additionally, Fuhrman grade and use of previous cytokines were independent prognostic factors of clinical outcome.

These data may be useful for improved patient management and treatment decision making, as well as stratification of patient 
groups in clinical trials, for better interpretation and application of outcomes of studies of TTs in patients with mRCC.

\section{ACKNOWLEDGEMENTS}

Editorial assistance was provided by Dene Simpson and Nadia Mirante of Content Ed Net; this assistance was funded by Bayer, Italy.

\section{REFERENCES}

Beck J, Procopio G, Bajetta E, Keilholz U, Negrier S, Szczylik C, Bokemeyer C, Bracarda S, Richel DJ, Staehler M, Strauss UP, Mersmann S, Burock K, Escudier B (2011) Final results of the European advanced renal cell carcinoma sorafenib (EU-ARCCS) expanded-access study: a large openlabel study in diverse community settings. Ann Oncol 22(8): 1812-1823

Choueiri TK, Garcia JA, Elson P, Khasawneh M, Usman S, Golshayan AR, Baz RC, Wood L, Rini BI, Bukowski RM (2007) Clinical factors associated with outcome in patients with metastatic clear-cell renal cell carcinoma treated with vascular endothelial growth factor-targeted therapy. Cancer 110(3): 543-550

Choueiri TK, Xie W, Kollmannsberger C, North S, Knox JJ, Lampard JG, McDermott DF, Rini BI, Heng DY (2011) The impact of cytoreductive nephrectomy on survival of patients with metastatic renal cell carcinoma receiving vascular endothelial growth factor targeted therapy. J Urol 85(1): 60-66

Dixon Jr JR (1998) The international conference on harmonization good clinical practice guideline. Qual Assur 6(2): 65-74

Escudier B, Eisen T, Stadler WM, Szczylik C, Oudard S, Siebels M, Negrier S, Chevreau C, Solska E, Desai AA, Rolland F, Demkow T, Hutson TE, Gore M, Freeman S, Schwartz B, Shan M, Simantov R, Bukowski RM (2007a) Sorafenib in advanced clear-cell renal-cell carcinoma. N Engl J Med 356(2): 125-134

Escudier B, Pluzanska A, Koralewski P, Ravaud A, Bracarda S, Szczylik C, Chevreau C, Filipek M, Melichar B, Bajetta E, Gorbunova V, Bay JO, Bodrogi I, Jagiello-Gruszfeld A, Moore N (2007b) Bevacizumab plus interferon alfa-2a for treatment of metastatic renal cell carcinoma: a randomised, double-blind phase III trial. Lancet 370(9605): 2103-2111

Flanigan RC, Salmon SE, Blumenstein BA, Bearman SI, Roy V, McGrath PC, Caton Jr JR, Munshi N, Crawford ED (2001) Nephrectomy followed by interferon alfa-2b compared with interferon alfa-2b alone for metastatic renal-cell cancer. $N$ Engl J Med 345(23): 1655-1659

Heng DY, Xie W, Regan MM, Warren MA, Golshayan AR, Sahi C, Eigl BJ, Ruether JD, Cheng T, North S, Venner P, Knox JJ, Chi KN, Kollmannsberger C, McDermott DF, Oh WK, Atkins MB, Bukowski RM, Rini BI, Choueiri TK (2009) Prognostic factors for overall survival in patients with metastatic renal cell carcinoma treated with vascular endothelial growth factor-targeted agents: results from a large, multicenter study. J Clin Oncol 27(34): 5794-5799

Ljungberg B, Mehle C, Stenling R, Roos G (1996) Heterogeneity in renal cell carcinoma and its impact on prognosis - a flow cytometric study. $\mathrm{Br} \mathrm{J}$ Cancer 74(1): 123-127

Manola J, Royston P, Elson P, McCormack JB, Mazumdar M, Negrier S, Escudier B, Eisen T, Dutcher J, Atkins M, Heng DY, Choueiri T, Motzer R, Bukowski R, International Kidney Cancer Working Group (2011) Prognostic model for survival in patients with metastatic renal cell carcinoma: results from the International Kidney Cancer Working Group. Clin Cancer Res 17: 5443-5450

Mekhail TM, Abou-Jawde RM, Boumerhi G, Malhi S, Wood L, Elson P, Bukowski R (2005) Validation and extension of the Memorial

\section{Conflict of interest}

Giuseppe Procopio received consultant fees and took part in advisory boards for Bayer Health Care, Pfizer, Novartis, GlaxoSmithKline. The remaining authors declare no conflict of interest.

Supplementary Information accompanies the paper on British Journal of Cancer website (http://www.nature.com/bjc)
Sloan-Kettering prognostic factors model for survival in patients with previously untreated metastatic renal cell carcinoma. J Clin Oncol 23(4): 832-841

Mickisch GH, Garin A, van Poppel H, de Prijck L, Sylvester R (2001) Radical nephrectomy plus interferon-alfa-based immunotherapy compared with interferon alfa alone in metastatic renal-cell carcinoma: a randomised trial. Lancet 358(9286): 966-970

Motzer RJ, Bacik J, Schwartz LH, Reuter V, Russo P, Marion S, Mazumdar M (2004) Prognostic factors for survival in previously treated patients with metastatic renal cell carcinoma. J Clin Oncol 22(3): $454-463$

Motzer RJ, Escudier B, Oudard S, Hutson TE, Porta C, Bracarda S, Grünwald V, Thompson JA, Figlin RA, Hollaender N, Urbanowitz G, Berg WJ, Kay A, Lebwohl D, Ravaud A (2008) Efficacy of everolimus in advanced renal cell carcinoma: a double-blind, randomised, placebocontrolled phase III trial. Lancet 372(9637): 449-456

Motzer RJ, Mazumdar M, Bacik J, Berg W, Amsterdam A, Ferrara J (1999) Survival and prognostic stratification of 670 patients with advanced renal cell carcinoma. J Clin Oncol 17(8): 2530-2540

Motzer RJ, Mazumdar M, Bacik J, Russo P, Berg WJ, Metz EM (2000) Effect of cytokine therapy on survival for patients with advanced renal cell carcinoma. J Clin Oncol 18(9): 1928-1935

Patil S, Figlin RA, Hutson TE, Michaelson MD, Négrier S, Kim ST, Huang X, Motzer RJ (2011) Prognostic factors for progression-free and overall survival with sunitinib targeted therapy and with cytokine as first-line therapy in patients with metastatic renal cell carcinoma. Ann Oncol 22(2): 295-300

Procopio G, Verzoni E, Bracarda S, Ricci S, Sacco C, Ridolfi L, Porta C, Miceli R, Zilembo N, Bajetta E (2011b) Sorafenib with interleukin-2 vssorafenib alone in metastatic renal cell carcinoma: the ROSORC trial. Br J Cancer 104(8): 1256-1261

Procopio G, Verzoni E, Iacovelli R, Guadalupi V, Gelsomino F, Buzzoni R (2011a) Targeted therapies used sequentially in metastatic renal cell cancer: overall results from a large experience. Expert Rev Anticancer Ther 11(11): 1631-1640

Rini BI, Escudier B, Tomczak P, Kaprin A, Hutson TE, Szczylik C, Tarazi JC, Rosbrook B, Kim S, Motzer RJ (2011) Axitinib versus sorafenib as second-line therapy for metastatic renal cell carcinoma (mRCC): results of phase III AXIS trial. J Clin Oncol 29, (abstr 4503)

Volpe A, Patard JJ (2010) Prognostic factors in renal cell carcinoma. World J Urol 28(3): 319-327

You D, Jeong IG, Ahn JH, Lee DH, Lee JL, Hong JH, Ahn H, Kim CS (2011) The value of cytoreductive nephrectomy for metastatic renal cell carcinoma in the era of targeted therapy. J Urol 185(1): 54-59

Yuasa T, Tsuchiya N, Urakami S, Horikawa Y, Narita S, Inoue T, Saito M, Yamamoto S, Yonese J, Fukui I, Nakano K, Takahashi S, Hatake K, Habuchi T (2012) Clinical efficacy and prognostic factors for overall survival in Japanese patients with metastatic renal cell cancer treated with sunitinib. BJU Int 109(9): 1349-1354

This work is published under the standard license to publish agreement. After 12 months the work will become freely available and the license terms will switch to a Creative Commons Attribution-NonCommercial-Share Alike 3.0 Unported License. 